\title{
Atık Tuğla Tozunun Mineral Katkı Olarak Kullanımının Kendiliğinden Yerleşen Betonun Taze Hal, Mekanik ve Durabilite Özelliklerine Etkisi
}

\author{
Murat TUYAN"1 \\ 1'̇zmir Demokrasi Üniversitesi, Mühendislik Fakültesi, İnşaat Mühendisliği Bölümü, 35140, İzmir, Türkiye
}

(Alınıș / Received: 01.04.2019, Kabul / Accepted: 24.07.2019, Online Yayınlanma / Published Online: 30.08.2019)

Anahtar Kelimeler

Kendiliğinden yerleșen beton, Atık tuğla tozu,

Uçucu kül,

Mekanik özellik,

Geçirimlilik,

Durabilite
Özet: $\mathrm{Bu}$ çalışmada, atık tuğla tozunun mineral katkı olarak kullanımının kendiliğinden yerleşen beton (KYB) özelliklerine etkisi incelenmiştir. Ayrıca, atık tuğla tozunun mineral katkı olarak performansının karşılaştırılması amacıyla uçucu kül katkılı KYB karışımları da üretilmiş ve bu betonların performansı ile kıyaslanmıştır. Bu amaçla, mineral katkı içermeyen kontrol karışımına ek olarak, çimentonun ağırlıkça \%15, \%30 ve \%45`i oranında atık tuğla tozu ikamesi ile oluşturulan KYB karışımları ve yine çimentonun ağırlıkça \%15, \%30 ve \%45`i oranında uçucu kül ikamesi ile üretilen KYB karıșımları hazırlanmıștır. Hazırlanan karıșımlar üzerinde, taze betonda çökme-yayılma deneyi, V hunisi deneyi, L kutusu deneyi ve sertleşmiş betonda ise 7, 28 ve 90 günlük basınç dayanımı tayini deneyi, 90 günlük eğilme dayanımı tayini deneyi, ultrases geçiş hızı deneyi, kapiler yolla su emme deneyi, permeabilite deneyi, hızlı klorür iyonu geçirimlilik deneyi, donmaçözülme ve yüksek sıcaklık direnci deneyi gerçekleştirilmiştir. Deney sonuçlarına göre, atık tuğla tozunun KYB karışımlarının işlenebilirliğini azalttığı belirlenmiştir. Çimento yerine \%15 atık tuğla tozu ikame edilerek oluşturulan KYB karışımının ileri yaştaki basınç dayanımı kontrol karışımına en yakın değere sahip karışım olmuştur. Atık tuğla tozu içeren karışımların su geçirimlilik özelliklerinin kontrol ve uçucu kül içeren karışımlardan daha zayıf olduğu sonucuna varılmıştır. Klorür iyonu geçirimliliği ve donma-çözülme ve yüksek sıcaklık direnci deneylerinde ise atık tuğla tozu içeren karışımların performansının kontrol karışımına göre daha iyi olduğu tespit edilmiştir.

\section{Effect of Use of Waste Clay Brick Powder as Mineral Admixture on Fresh, Mechanical and Durability Properties of Self-Consolidating Concrete}

\section{Keywords}

Self-consolidating concrete, Waste clay brick powder, Fly ash,

Mechanical properties, Permeability, Durability

\begin{abstract}
In this study, the effect of use of waste brick powder as a mineral admixture on self-consolidating concrete (SCC) properties was investigated. In addition, in order to compare the performance of the waste brick powder as a mineral admixture, SCC mixtures incorporating fly ash were produced and the performance of such concretes was compared. For this purpose, control SCC mixture and SCC mixtures formed by the substitution of waste brick powder at 15\%, 30\% and $45 \%$ by weight of the cement, and the fly ash substitution at $15 \%, 30 \%$ and $45 \%$ by weight of the cement were prepared. Slump flow test, V-funnel flow time test, Lbox passing ratio test, compressive strength test at 7,28 and 90-days, flexural strength test at 90-day, ultrasound pulse velocity test, sorptivity test, permeability test, rapid chloride ion permeability test, freeze-thaw resistance test and high temperature resistance test were performed on the SCC mixtures. It was determined that waste brick powder reduced the workability of the SCC mixtures. The compressive strength of the SCC mixture having $15 \%$ waste brick powder replaced with cement was the closest to the control mixture. It has been concluded that the water permeability properties of SCC mixtures containing waste brick powder were weaker than those of the SCC control and fly ash blended mixtures. Regarding the chloride ion permeability, freeze-thaw resistance and high temperature resistance tests, the performance of SCC mixtures with waste brick powder was found to be better than the control mixture.
\end{abstract}




\section{Giriş}

Kendiliğinden yerleșen beton (KYB), 1980'li yılların başında Japonya`da geliștirilen özel bir beton türüdür. KYB’nin üstün akış özellikleri, betonun kalıplara kolay bir şekilde yerleşmesini sağlayarak, geleneksel betona göre en büyük avantajı olmaktadır [1]. KYB'nin taze halde gösterdiği üstün performansı daha boşluksuz bir beton meydana gelmesini sağlayarak sertleşmiş beton özelliklerini de olumlu etkilemektedir [2]. KYB'nin bu üstün akış özelliği temel olarak yüksek oranda bağlayıcı malzeme içeriği ve yeni nesil süperakışkanlaştırıcı katkı malzemesi ile sağlanmaktadır [3]. Beton kimyasal katkı malzemesi üretim teknolojisinin her geçen gün gelişmesiyle birlikte kimyasal katkıların maliyetleri de zaman içerisinde azalmaktadır. Bunun sonucunda betonun çeşitli özelliklerini geliştiren bu katkı malzemeleri beton sektöründe daha çok kullanılmaya başlanmıştır [4]. Bununla birlikte KYB'nin beton sektöründe kullanımı da yıllar içerisinde artış göstermektedir.

KYB'nin geleneksel betona göre teknik anlamda pek çok avantajı olmasına rağmen, özellikle çimento dozajının normal betonlara göre fazla olması bu betonların maliyetini arttırmaktadır [5]. Bu maliyetleri azaltmak amacıyla çimentonun yerine pek çok mineral katkı malzemesi ikame edilerek bu tür betonların performansı belirlenmektedir [6, 7]. Çimentonun yerine mineral katkı malzemesi ikame edilmesi sonucunda daha karmaşık bir hidratasyon yapısına sahip bağlayıcı sistemler ortaya çıkmaktadır. Mineral katkı olarak kullanılan malzemenin tane boyutu, şekli, kimyasal ve mineralojik kompozisyonu ile tanecikler arası boşluk yapısı gibi birçok özelliği bağlayıcı yapının özelliklerini etkilemektedir [8].

Tuğla, betondan sonra inşaat sektöründe en fazla kullanılan yapı malzemelerinden bir tanesidir. Tuğlanın üretim aşamasında ve mevcut binaların yıkımı esnasında oldukça fazla tuğla kırığı ortaya çımaktadır. $\mathrm{Bu}$ atık malzemenin bertaraf edilmesi çevre açısından oldukça önemli hale gelmektedir. Bu amaçla, tuğla kırıklarının inşaat sektöründe tekrar kullanımına yönelik son yıllarda pek çok çalışma gerçekleştirilmiştir. Yapılan çalışmalarda, atık tuğla kırıkları hem agrega hem de çimento yerine kullanılmıştır. Doğal agrega yerine atık tuğla kırıklarının kullanıldığı çalışmalarda, tuğlanın yapısı gereği çok boşluklu bir malzeme olmasından dolayı doğal agrega yerine kullanımının artmasıyla beton karışımının su ihtiyacının oldukça arttığı sonucuna varılmıştır. Agrega yerine tuğla kırığının kullanıldığı çalışmalar değerlendirildiğinde, agrega yerine ağırlıkça \%20'den fazla tuğla kırığı kullanılmasının betonun mekanik performansını olumsuz yönde etkilediği belirlenmiştir. Atık tuğla kırığının uygun inceliğe getirilip çimento yerine mineral katkı malzemesi olarak kullanılması sonucunda genel olarak atık tuğla tozu miktarı belirli bir seviyeye geldikten sonra betonların mekanik özelliğinin önemli ölçüde azaldığı yapılan çalışmalar sonucunda tespit edilmiştir. Atık tuğla tozunun çimento yerine kullanılması ile yapılan çalışmalarda genel olarak çimento yerine ağırlıkça \%20`den fazla atık tuğla tozunun kullanılması sonucu betonların mekanik özelliklerinde bir düşüş meydana geldiği sonucuna varılmıştır [9].

Heikal vd. [10] tarafından yapılan çalışmada, çimentonun yerine ağırlıkça \%12.5, \%25 ve \%37.5 oranında atık tuğla tozu kullanılarak KYB karışımları üretilmiştir. Üretilen betonların basınç dayanımı ve reolojik özellikleri incelenmiştir. Atık tuğla tozu içeriğinin artması sonucunda karışımların basınç dayanımı kademeli olarak azalmıştır. Ayrıca, atık tuğla tozu içeriğinin artması sonucu taze beton karışımların kayma gerilmesinin kademeli olarak arttığ bildirilmiştir.

Uluslararası literatürde kendiliğinden yerleşen betonda atık tuğla tozunun kullanımı ile ilgili az sayıda çalışma olmasından dolayı ve bu çalışmalarda bu tür betonların geçirimlilik, donma-çözülme ve yüksek sıcaklık direnci özelliklerinden bahsedilmemesinden dolayı literatürdeki bu açığı kapatmaya yönelik olarak bu çalışma gerçekleștirilmiştir. Yapılan çalışmada çimento yerine ağırlıkça \%15, \%30 ve \%45 oranında atık tuğla tozu veya uçucu kül ikame edilen KYB karışımları üzerinde taze hal deneyleri, basınç dayanımı tayini, eğilme dayanımı tayini, geçirimlilik, donma-çözülme direnci ve yüksek sicaklık direnci deneyleri gerçekleştirilmiştir.

\section{Materyal ve Metot}

\subsection{Kullanılan malzemeler}

Deneysel çalışmada, CEM I 42.5R tipi çimento kullanılmıştır. Ayrıca, Manisa Turgutlu yöresinde bulunan tuğla fabrikalarından temin edilen atık tuğla kırıkları uygun inceliğe getirilip mineral katkı olarak kullanılmıştır. Çalışmada kullanılan diğer mineral katkı ise Soma Termik Santrali'nden temin edilen C tipi uçucu kül olmuştur. Çimento, atık tuğla tozu (ATT) ve uçucu külün (UK) kimyasal ve fiziksel özellikleri Tablo 1'de verilmiştir.

Atık tuğla tozu ve uçucu külün morfolojik yapısı Şekil 1'de gösterilmiştir. Genel olarak, atık tuğla tozunun köşeli, uçucu külün ise küresel taneciklere sahip olduğu belirlenmiştir.

Çalışmada KYB üretimi için iki farklı agrega tane boyutuna sahip agrega kullanılmıştır. İnce agrega olarak 0-4 mm tane boyutlu kırma kireçtaşı ve iri agrega olarak 4-16 mm tane boyutlu kırma kireçtaşı kullanılmıştır. Her iki agreganın bazı fiziksel özellikleri Tablo 2'de verilmiştir.

KYB karışımlarında akışkanlığı sağlamak amacıyla polikarboksilik eter esaslı süperakışkanlaştırıcı kimyasal katkı malzemesi kullanılmıştır. 
Tablo 1. Çimento, atık tuğla tozu ve uçucu külün kimyasal ve fiziksel özellikleri

\begin{tabular}{cccc}
\hline Kimyasal bileşim (\%) & Çimento & ATT & UK \\
\hline $\mathrm{SiO}_{2}$ & 20.1 & 50.3 & 32.8 \\
$\mathrm{Al}_{2} \mathrm{O}_{3}$ & 5.7 & 22.0 & 13.8 \\
$\mathrm{Fe}_{2} \mathrm{O}_{3}$ & 2.2 & 6.9 & 4.8 \\
$\mathrm{CaO}$ & 64.1 & 12.4 & 39.7 \\
$\mathrm{MgO}$ & 1.5 & 3.4 & 2.1 \\
$\mathrm{SO}_{3}$ & 3.1 & 0.2 & 4.2 \\
$\mathrm{Na}_{2} \mathrm{O}$ & 0.3 & 0.6 & 0.4 \\
$\mathrm{~K}_{2} \mathrm{O}$ & 0.9 & 2.6 & 1.2 \\
$\mathrm{Cl}$ & 0.006 & 0.009 & 0.008 \\
Kızdırma kaybı & 1.7 & 1.6 & 1.1 \\
\hline Özgül ağırlık & 3.10 & 2.70 & 2.53 \\
Blaine incelik (g/cm) & 3210 & 5500 & 3580 \\
\hline
\end{tabular}
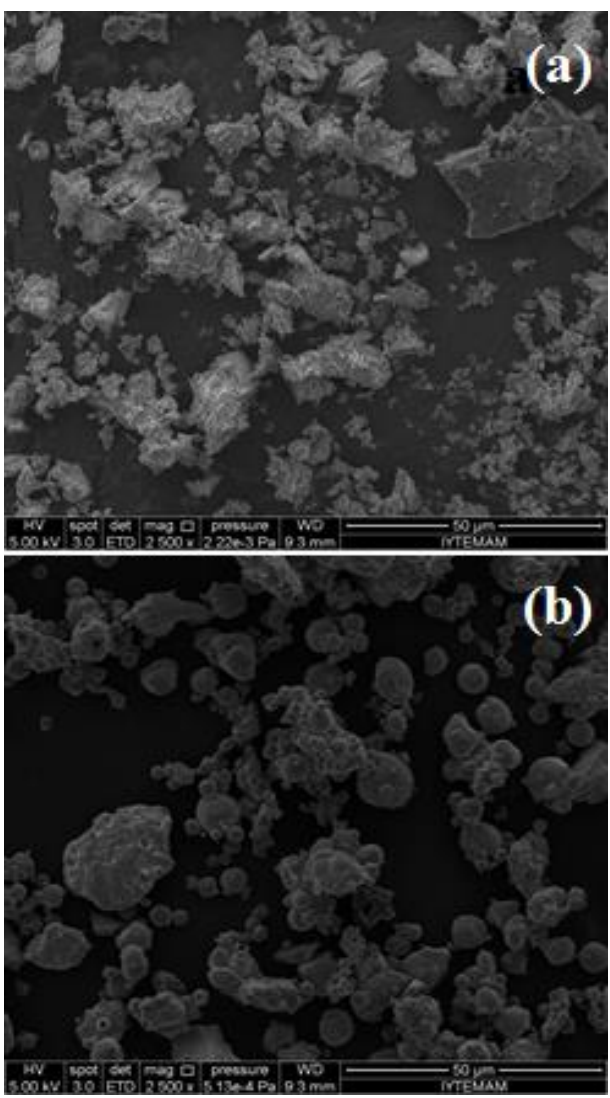

Şekil 1. ATT (a) ve UK'nın (b) morfolojik yapıları

Tablo 2. Kırma kireçtașı agregasının fiziksel özellikleri

\begin{tabular}{ccc}
\hline Özellik & İri agrega & İnce agrega \\
\hline Kuru özgül ağırlık $\left(\mathrm{kg} / \mathrm{m}^{3}\right)$ & 2650 & 2600 \\
Su emme (\%) & 0.21 & 0.67
\end{tabular}

\subsection{Karışım oranları}

Deneysel çalışmada toplam yedi adet beton serisi olușturulmuștur. Üretilen KYB'lerin taze beton birim hacim ağırlıklarına göre düzeltilmiş karışım oranları Tablo 3.'te verilmiştir. KYB karışımlarının malzeme tasarım oranları EFNARC [11] kılavuzuna göre belirlenmiştir. Tüm beton serilerinde su/bağlayıcı (çimento + atık tuğla tozu veya uçucu kül) oranı 0.40 olarak sabit tutulmuștur. Kontrol serisi dışında mineral katkı olarak çimentonun ağırlıkça \%15, \%30 ve \%45 oranında atık tuğla tozu veya uçucu kül kullanılmıştır. Beton karışımlarının kodları; içerisinde atık tuğla tozu varsa ATT, uçucu kül varsa UK şeklinde belirlenmiștir. Örneğin, ATT-30 serisi atık tuğla tozunun ağırlıkça \%30 oranında çimento ikamesi ile oluşan beton karıșımını temsil etmektedir.

\subsection{KYB karışımlarının hazırlanması}

KYB üretmek amacıyla karıştırıcıya sırasıyla iri agrega, ince agrega, çimento, atık tuğla tozu/uçucu kül konulup homojen bir karışım elde etmek için bir dakika karıștırılmıştır. Kuru karışım oluşturulduktan sonra karışım suyunun yarısı kuru karışıma ilave edilerek iki dakika karıștırılmıș, suyun geri kalan kısmına süperakışkanlaştırıcı katkı eklenerek karıșıma ilave edilmiș ve iki dakika daha karıștırılarak toplam beș dakikada karıștırma işlemi tamamlanmıştır.

Taze beton üzerinde çökme yayılma deneyi, V-hunisi deneyi ve L-kutusu deneyi gerçekleştirilmiştir. Daha sonra taze beton karışımı kalıplara yerleştirilmiş ve bir gün sonra sertleşmiş betonlar kalıptan çıkartılarak $20 \pm 2^{\circ} \mathrm{C}$ sıcaklıkta ve $\% 95$ bağıl nem ortamında su kürüne tabi tutulmuștur. Beton numuneler 7, 28 ve 90 gün sonra kürden alınarak sertleşmiş beton deneylerine uygulanmıştır.

\subsection{Deney yöntemleri}

Taze KYB karışımları üzerinde EFNARC [11] kılavuzuna göre sırasıyla çökme yayılma deneyi, Vhunisi deneyi ve L-kutusu deneyi gerçekleştirilmiștir. Sertleşmiş beton üzerinde basınç dayanımı tayini TS EN 12390-3 [12] standardındaki hususlar dikkate alınarak $100 \mathrm{~mm}$ ayritlı küp numuneler üzerinde gerçekleştirilmiştir. $100 \mathrm{~mm}$ ayrıtlı küp numuneler üzerinde yapılan ultrases geçiş hızı tayini deneyi ASTM C597 [13] standardina uygun olarak gerçekleştirilmiştir. Kapiler yolla su emme tayini 100 $\mathrm{mm}$ ayrıtlı küp beton numuneler üzerinde ASTM C1585 [14] standardında belirtilen esaslara göre uygulanmıştır. $150 \mathrm{~mm}$ boyutlu küp numuneler üzerinde basınç altında su geçirimlilik deneyi TS EN 12390-8 [15] standardına göre gerçekleştirilmiştir. Hızlı klorür iyonu geçirimlilik deneyi $100 \mathrm{~mm}$ çap ve $50 \mathrm{~mm}$ yüksekliğe sahip beton numuneler üzerinde ASTM C1202 [16] standardına göre gerçekleştirilmiştir. Donma çözülme deneyi, ASTM C 666 [17] standardına göre $100 \mathrm{~mm}$ boyutlu küp beton numuneler üzerinde toplamda 150 çevrim donma-çözülme etkisine maruz bırakarak gerçekleştirilmiştir. KYB karışımlarının yüksek sicaklık direncini belirlemek amaciyla numuneler $150^{\circ} \mathrm{C}, 300^{\circ} \mathrm{C}, 600^{\circ} \mathrm{C}$ ve $900^{\circ} \mathrm{C}$ sıcaklıklarda üç saat boyunca yüksek sıcaklığa maruz bırakılmıștır. Hedeflenen sıcaklığa ulaşıncaya kadar sıcaklık artışı $5^{\circ} \mathrm{C} /$ dakika olarak belirlenmiştir. 
Tablo 3. Düzeltilmiș karıșım oranları (Değerler $1 \mathrm{~m}^{3}$ için verilmiștir.)

\begin{tabular}{cccccccc}
\hline & Kontrol & ATT-15 & ATT-30 & ATT-45 & UK-15 & UK-30 & UK-45 \\
\hline Çimento $(\mathrm{kg})$ & 493 & 421 & 344 & 271 & 421 & 348 & 272 \\
Su (kg) & 197 & 198 & 197 & 197 & 198 & 199 & 198 \\
Uçucu kül $(\mathrm{kg})$ & 0 & 0 & 0 & 0 & 74 & 149 & 223 \\
Atık tuğla tozu $(\mathrm{kg})$ & 0 & 74 & 148 & 222 & 0 & 0 & 0 \\
0/4 agrega DYK* $(\mathrm{kg})$ & 797 & 787 & 769 & 760 & 789 & 781 & 767 \\
4/16 agrega DYK* $(\mathrm{kg})$ & 806 & 796 & 778 & 768 & 798 & 790 & 777 \\
Akıșkanlaștırıcı $(\mathrm{kg})$ & 8 & 9 & 9 & 10 & 6 & 6 & 5 \\
\hline TOPLAM $(\mathrm{kg})$ & 2301 & 2285 & 2244 & 2228 & 2286 & 2271 & 2242 \\
\hline
\end{tabular}

* DYK: Doygun yüzey

Yüksek sıcaklık uygulanan numuneler oda sıcaklığına ulaştığında basınç dayanımları belirlenmiş ve betonların dayanım kayıplarındaki değişim incelenmiştir. Mekanik ve durabilite özelliklerinin belirlenmesi için gerçekleştirilen tüm deneylerde her beton serisi için 3 adet numune kullanılmış ve deney sonuçlarında bunların ortalaması belirtilmiştir.

\section{Bulgular ve Tartışma}

Çalışmada KYB karışımlarının taze hal özellikleri incelenmiştir. Tüm karışımların çökme yayılma değerleri $650 \mathrm{~mm} \pm 20 \mathrm{~mm}$ olacak şekilde üretilmiştir. Hedef çökme yayılma değeri elde etmek amacıyla her karıșım için farklı miktarda süperakışkanlaştırıcı katkı maddesi kullanılmıştır (Tablo 3). Karışımlarda hedef çökme yayılma değerini sağlamak için kullanılan süperakışkanlaştırıcı miktarları incelendiğinde ATT katkılı KYB karıșımlarında kontrol karışımına göre daha fazla katkı kullanıldığı anlaşılmaktadır. Bir başka deyişle, KYB karışımlarında ATT kullanımı arttıkça karıșımların işlenebilirlikleri azalmıştır. ATT'nin boşluk yapısının çimentoya göre daha fazla olmasının, bunun önemli sonuçlarından biri olduğu düşünülmektedir. UK esaslı KYB karışımlarının çökme yayılma deneyi sonuçlarında ise kontrol karışımına göre daha az süperakışkanlaştırıcı katkı ihtiyacı meydana gelmiştir. Şekil 1'de UK partiküllerinin genel olarak küresel bir yapıya sahip olduğu görülmektedir. Dolayısıyla, küresel yapıdaki UK'nın kullanılmasının beton karışımının işlenebilirlik özelliğini iyileștirildiği söylenebilir. Ayrıca, yine Şekil 1'de görüldüğü gibi, ATT UK'ya göre daha köşeli bir yapıya sahiptir ve ATT esaslı karışımlarının işlenebilirliğini azaltan önemli bir faktörün de bu morfolojik yapıdan kaynaklandığı düşünülmektedir.

KYB karışımlarının V-hunisi deneyi sonuçları Şekil 2'de gösterilmiștir. V-hunisi deneyi KYB'nin viskozitesi ve akıcılık özellikleri hakkında fikir edinmemizi sağlamaktadır [11]. Aynı çökme yayılma değerine sahip karışımların viskoziteleri farklı olabilmektedir. Nitekim deney sonuçları da bu durumu doğrulamaktadır. KYB karışımlarında ATT kullanımı sonucunda V-hunisi geçiş suresinde ciddi oranda artış gözlemlenmiştir. ATT kullanımı sonucunda karışımda kullanılan süperakışkanlaştırıcı miktarının artması sonucu karışımların viskozitesi de artmıştır. UK kullanımda ise yine kontrol numunesine göre daha yüksek V-hunisi geçiş suresi değeri elde edilmesine rağmen, bu süreler ATT katkılı karışımlara göre oldukça düşük seviyede kalmıştır. UK esaslı karışımlarda kontrol karışımına göre daha az süperakışkanlaştırıcı katkı kullanılmasına rağmen, V-hunisi geçiş süresi kontrol karışımına göre daha fazla çıkmıştır. Bu durum UK kullanımı sonucunda KYB karışımlarının kohezifliğinin arttığını göstermektedir. 5 dakika gecikmeli V-hunisi geçiş süresi değerlerine bakılacak olursa, kontrol karışımında diğer katkılı karışımlara göre gecikmeli geçiş süresinin ilk geçiş süresine oranı daha fazla olmuştur. Bunun en önemli nedeninin, hem ATT hem de UK katkılı karışımların kontrol karışımına göre daha kohezif olmasından kaynaklandığ düşünülmektedir. Gecikmeli V-hunisi geçiş süresi KYB karışımlarının ayrışma direnci ile ilişkilendirilmektedir [18]. Sonuç olarak, viskoziteleri kontrol karışımına göre daha yüksek olan ATT ve UK katkılı karışımların ayrışma dirençlerinin de kontrol karışımına göre daha fazla olduğu tespit edilmiştir.

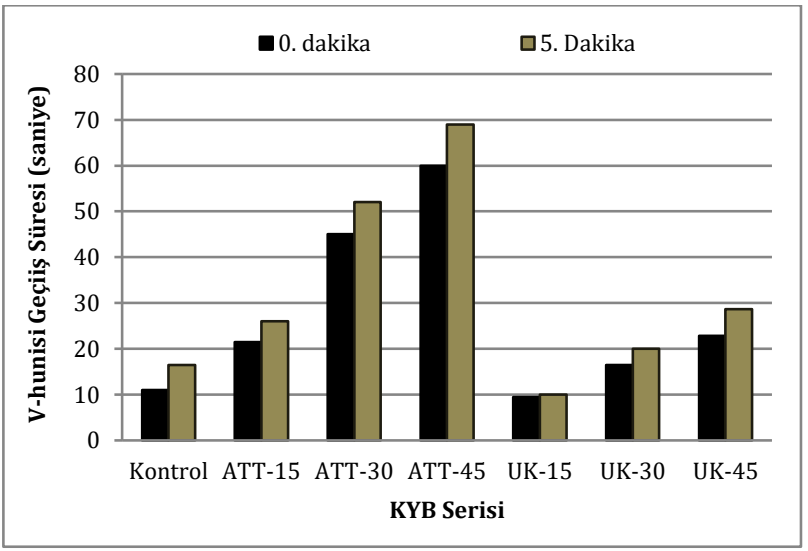

Şekil 2. KYB karışımlarının V-hunisi deneyi sonuçları

KYB karışımlarının L-kutusu deney sonuçları Şekil 3'te verilmiştir. L-kutusu deneyi, KYB karışımlarının donatılar arası geçiş yeteneğini belirlemek için gerçekleştirilmektedir. Ayrıca, karışımın geçiş esnasında ayrışma direnci de gözlemlenmiş olmaktadır. KYB'nin L-kutusu oranı ne kadar yüksek olursa karıșımın geçiș yeteneğinin o kadar fazla olduğu sonucuna varılmaktadır [11]. Çalışmada üretilen karışımların L-kutusu deney sonuçlarına göre, ATT katkılı KYB karışımlarının geçiş özelliği kontrol karıșımına göre daha az olduğu gözlemlenmiştir. V-hunisi deneyinde olduğu gibi bu deneyde de ATT kullanımı sonucunda KYB 
karıșımlarının taze hal özelliklerinin olumsuz etkilendiği belirlenmiştir. EFNARC [11] kılavuzuna göre, L-kutusu oranının 0.8`den az olmaması önerilmektedir. Bu durumda, KYB karıșımlarında çimento yerine ağırlıkça \%45 ATT kullanımının uygun olmadığı sonucu varılmıştır. UK katkılı karışımların deney sonuçlarına bakılacak olursa, \%15 ve \%30 UK katkılı karışımlar kontrol karışımına yakın özellikler göstermiştir. \%45 UK katkılı karışımda ise L-kutusu oranı değeri, diğer karışımlara göre düşmesine rağmen, alt sınır olan 0.8 değerinin üstünde kalmıştır.

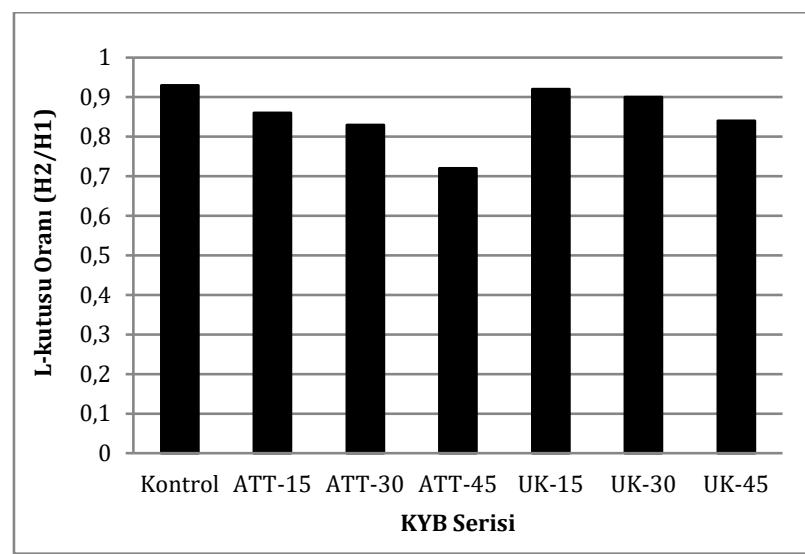

Şekil 3. KYB karışımlarının L-kutusu deneyi sonuçları

KYB karışımlarının 7, 28 ve 90 günlük basınç dayanımı sonuçları Şekil 4'te sunulmuştur. Genel olarak, tüm yaşlar için, KYB karışımlarında ATT kullanımı arttıkça basınç dayanımlarında kademeli olarak bir azalma gözlemlenmiștir. Çimento yerine mineral katkı malzemesi kullanımı ile ilgili olarak yapılan önceki çalışmalarda, mineral katkı miktarının artmasıyla betonların basınç dayanımındaki kademeli azalmasının nedeninin bağlayıcı üründe (CSH) meydana gelen dilüsyon (seyreltme) etkisinden olduğu bildirilmiştir [20]. ATT’nin kimyasal yapısından (yüksek $\mathrm{SiO}_{2}$ oranı) dolayı puzolanik özellik gösterme potansiyeli literatürden de bilinmektedir [21]. Ancak, çimento yerine \%30`dan fazla ATT kullanımının karışımların basınç dayanımını ciddi oranda düşürdüğü belirlenmiştir. 90 günlük deney sonuçlarına göre, kontrol karışımına kıyasla ATT katkılı karışımlarda dayanım düşüşü $\% 15, \% 30$ ve $\% 45$ ikame oranları için sırasıyla \%3.3, $\% 5.7$ ve $\% 14.2$ oranında meydana gelmiştir. 7 günlük erken yaş basınç dayanımları kıyaslanacak olursa, kontrol karışımına göre ATT’nin \%15, \%30 ve \%45 oranında ikame edilmesiyle elde edilen karışımların dayanımları sırasıyla, \%8.1, \%18.1 ve \%31.1 oranında düşük çıkmıştır. Puzolanik yapıdaki malzemelerin betonun ileri yaştaki dayanımlarına katkısı erken yaș dayanımlarına göre daha fazla olmaktadır [19]. ATT'nin KYB karıșımlarında çimento yerine kullanılması sonucunda da bu etkinin meydana geldiği gözlemlenmiştir. KYB karışımlarında UK kullanımı sonucunda tüm yaştaki betonlar için kontrol karışımına göre dayanımlarda düşüşler meydana gelmiştir. 7 günlük erken yaştaki kontrol betonuna göre UK'nın $\% 15, \% 30$ ve $\% 45$ oranında ikame edilmesiyle üretilen betonların dayanımları sırasıyla, \%5.2, \%16.5 ve \%27.7 oranında düşük elde edilmiştir. 90 günlük ileri yașta ise dayanımlardaki düşüş oranı azalarak, kontrol betonuna göre UK'nın $\% 15, \% 30$ ve $\% 45$ oranında ikame edilmesiyle üretilen betonların dayanımları sırasıyla, $\% 0, \% 3.4$ ve \%8.9 oranında meydana gelmiștir. Deney sonuçlarına göre, UK katkılı karışımların basınç dayanımları tüm yaşlar için ATT katkılı karışımlardan daha yüksek çıkmıştır.

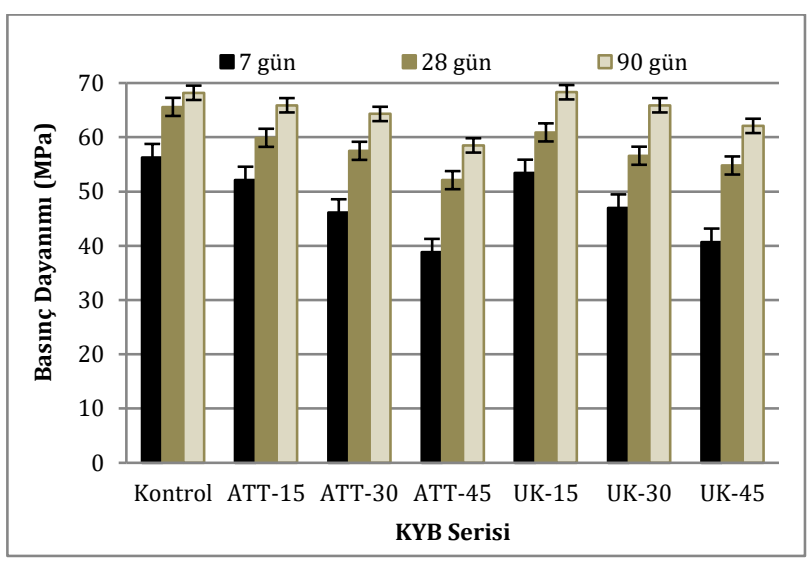

Şekil 4. KYB karışımlarının basınç dayanımı sonuçları

KYB karıșımlarının eğilme dayanımı sonuçları Şekil 5'te verilmiştir. Şekilden de görüldüğü gibi, ATT katkılı KYB karışımlarının eğilme dayanımları kontrol karışımından düşük çıkmıştır. KYB karışımlarında ATT oranı arttıkça eğilme dayanımlarında kademeli olarak bir azalma meydana gelmiștir. UK katkılı karışımlarda ise \%15 UK katkılı karışımın eğilme dayanımı kontrol karışımının eğilme dayanımına yakın değer almıştır. UK oranı arttıkça dayanımlarda kademeli olarak düşüşler gözlemlenmiştir. Karıșımların eğilme/basınç dayanımı oranları da Şekil 5'te gösterilmiştir. Kontrol karıșımının eğilme/basınç dayanımı \%19.1 olarak belirlenmiştir. ATT katkılı karışımlarda eğilme/basınç dayanımı oranı ise $\% 15, \% 30$ ve $\% 45$ ATT katkı oranları için sirasiyla \%19.3, \%19.5 ve \%19.4 olarak hesaplanmıştır. ATT katkılı karışımların eğilme/basınç dayanımı oranı kontrol karışımından bir miktar fazla olduğu tespit edilmiştir. UK katkılı KYB karışımlarında ise bu oran \%15, \%30 ve \%45 UK katkı oranları için sırasıyla \%19, \%18.8 ve \%19 olarak belirlenmiştir. ATT esaslı KYB karışımlarının eğilme/basınç dayanımı oranının kontrol ve UK katkılı KYB karıșımlarından daha yüksek olmasının ATT'nin gözenekli yapısından dolayı daha güçlü bir ara yüzeye neden olduğundan kaynaklandığı düşünülmektedir. Bilindiği gibi, güçlü ara yüzeyin eğilme ve çekme dayanımına basınç dayanımından fazla olumlu etkisi bulunmaktadır [22].

KYB karışımlarının ultrases geçiş hızı deneyi sonuçları Şekil 6'da gösterilmiştir. Deney sonuçlarına göre, ultrases geçiş hızı değerlerinin ATT katkılı karışımlarda kontrol karışımına göre azaldığı tespit 
edilmiştir. Kontrol karışımının ultrases geçiş hızı değeri $4900 \mathrm{~m} / \mathrm{s}$ olarak ölçülürken, \%15 ATT ikameli karışımda bu değer 4739 m/s ye düşmüștür. \%30 ve \%45 ATT katkılı KYB karışımlarında ise sırasıyla $4717 \mathrm{~m} / \mathrm{s}$ ve $4697 \mathrm{~m} / \mathrm{s}$ değerleri ölçülmüştür. KYB karışımlarında \%15 ATT kullanımında kontrol karışımına göre ultrases geçiş hızı değerinde önemli bir azalma olmasına rağmen, $\% 30$ ve \%45 ATT katkılı karışımlarda hızların doğrusal olarak kademeli bir seklide azalmadığı tespit edilmiştir. UK katkılı KYB karıșımların deney sonuçlarına bakılacak olursa, \%15 UK katkılı karışımda ultrases geçiş hızının kontrol karışımı ile neredeyse ayni değere ( 4900 m/s) sahip olduğu belirlenmiştir. \%30 ve \%45 UK katkılı karışımlarda ise bu değerler sırasıyla $4878 \mathrm{~m} / \mathrm{s}$ ve $4833 \mathrm{~m} / \mathrm{s}$ olarak ölçülmüş ve kademeli bir şekilde bu değerlerin azaldığı tespit edilmiştir. ATT ve UK katkılarının ultrases geçiş hızı deney sonuçları karşılaştırıldı̆̆ında, ATT katkılı KYB karışımlarının ultrases geçiş hızlarının UK katkılı karışımların geçiş hızlarına göre daha düşük olduğu tespit edilmiştir. Ultrases geçiş hızı deneyinde betonun içerisinden ses dalgasının ne kadar sürede geçtiği belirlenmektedir. Yani, bu deney betonun boşluk yapısı hakkında fikir vermektedir [18]. Deney sonuçlarına bakıldığında, ATT katkılı karışımların kontrol ve UK katkılı karışımlara göre çok daha fazla boşluk yapısına sahip olduğunu söylenebilir. KYB karışımlarında kullanılan çimento, ATT ve UK toz malzemeleri arasında en boşluklu yapıya sahip olanın ATT olduğu sonucuna varlabilir.

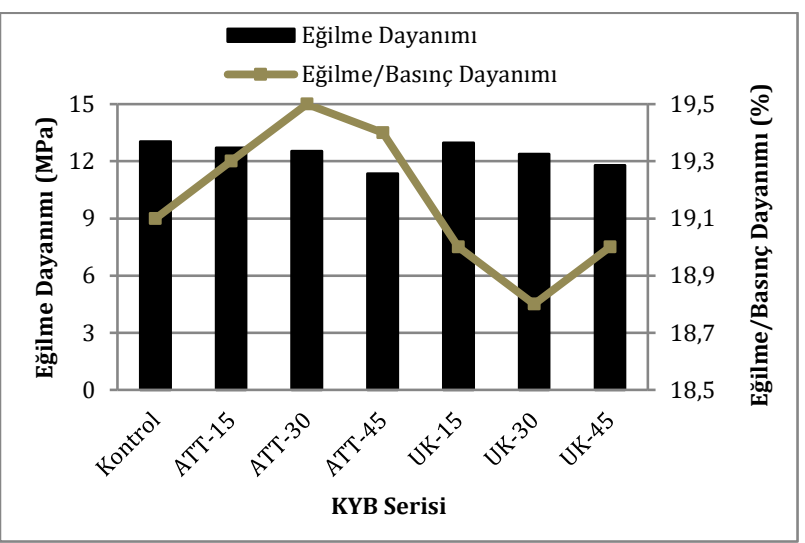

Şekil 5. KYB karışımlarının eğilme dayanımı sonuçları

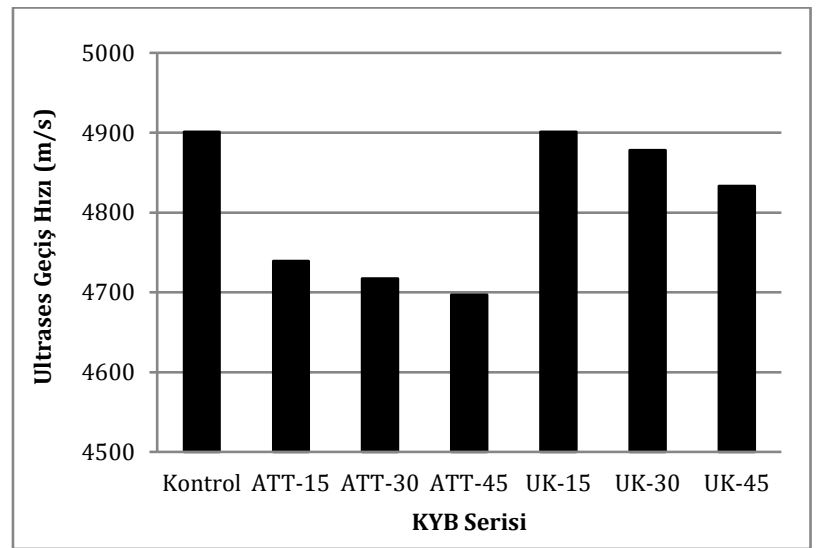

Şekil 6. KYB karışımlarının ultrases geçiş hızı deneyi sonuçları
Kontrol ve ATT katkılı KYB karışımlarının kapiler yolla su emme deneyi sonuçları Şekil 7`de sunulmuştur. Tüm karışımların kılcallık katsayılarında zamana bağlı olarak bir artış gözlemlenmiștir. Tüm karıșımlarda 6 günlük kılcallığının büyük bir çoğunluğunun ilk bir gün içerisinde meydana geldiği tespit edilmiştir. Deneye başlanan süreden itibaren deney sonuna kadar ATT katkılı tüm karışımların kılcallık katsayılarının kontrol karıșımına göre daha fazla olduğu tespit edilmiştir. 6 gün sonunda karışımların kılcallık katsayıları kıyaslandığında ise \%15 ile \%30 ATT katkılı karışımların kılcallık katsayılarının kontrol karışımına göre sırasıyla \%13 ve $\% 26$ oranında fazla olduğu belirlenmiştir. \%45 ATT ikamesi ile üretilen KYB karışımda ise kılcallık katsayısı 6 gün sonunda kontrol karışımına göre \%74 oranında fazla çıkmıştır. Deney sonuçlarına göre, \%15 ve \%30 ATT ikamesinin karışımların kılcal yolla su emmesini belirli oranda arttırdığı, \%45 ATT ikamesinin ise KYB karışımında kılcallığı önemli derece arttığ gözlemlenmiștir.

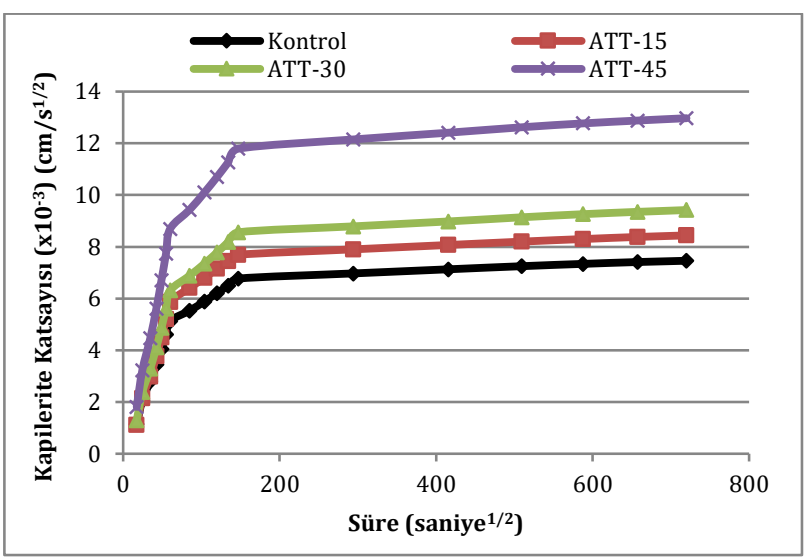

Şekil 7. Kontrol ve ATT katkılı KYB karışımlarının kapiler yolla su emme deneyi sonuçları

Kontrol ve UK katkılı KYB karışımlarının kapiler yolla su emme deneyi sonuçları Şekil 8`de gösterilmiştir. UK katkılı karışımların deney süresince kılcallık katsayısının kontrol karışımından daha düşük olduğu tespit edilmiştir. 6 gün sonunda UK katkılı KYB karışımlarının kılcallık katsayıları \%15, \%30 ve \%45 ikame oranları için kontrol karışımından sırasıyla $\% 10, \% 16$ ve $\% 52$ oranında daha düşük değerler almıştır. ATT ve UK katkılı karıșımların kapiler yolla su emme özellikleri karşılaştırıldığında, ATT katkılı karışımların UK katkılı karışımlara nazaran kılcallığının oldukça fazla olduğu söylenebilir.

KYB karışımlarının permeabilite deneyi sonuçları Şekil 9`da verilmiştir. Deneyde betonların 72 saat sonunda basınç altında su işleme derinlikleri belirlenmiştir. Basınç altında permeabilite deneyi betonun bünyesinde bulunan birbiri ile bağlantılı açık boşluklar hakkında fikir sağlamaktadır [18]. Deney sonuçlarına göre, çimento yerine belirli oranda ATT ve UK ikame edilen karışımlarda ikame oranı arttıkça KYB karışımlarının permeabilitesinin arttığı gözlemlenmiştir. Kontrol karışımının su işleme derinliği değeri 10.9 mm ölçülürken ATT katkılı 
karışımlarda \%15, \%30 ve \%45 ikame oranlarına sahip karışımlarda bu değerler sırasıyla $16 \mathrm{~mm}, 24.2$ mm ve $31.2 \mathrm{~mm}$ olarak ölçülmüştür. UK katkılı karışımlarda ise UK ikamesi \%15 olan karışımda 8.8 $\mathrm{mm}$ \%30 olan karışımda $15.7 \mathrm{~mm}$ ve \%45 olan karışımda ise $23.6 \mathrm{~mm}$ su işleme derinliği değeri belirlenmiştir. Deney sonuçlarına göre, ATT katkılı KYB karışımlarının basınç altında permeabilitesi UK katkılı karışımlardan daha fazla olduğu tespit edilmiştir. UK katkılı karışımların kapiler yolla su emme ve basınç altında permeabilite deney sonuçları incelendiğinde, bu karışımların kılcallık katsayısının kontrol karışımından düşük çıkmasına rağmen, basınç altında permeabilite değeri kontrol karışımından fazla çıkmıştır. Bu sonuca göre, UK katkılı karışımların kılcal boşlukları kontrol karışımına göre daha az olmasına rağmen, bağlantılı açık boşlukları kontrol numunesine göre daha fazla olduğu belirlenmiştir. ATT katkılı KYB karışımlarında ise bu iki geçirimlilik deneyi sonuçlarının da kontrol betonuna göre daha fazla çıktığı tespit edilmiştir.

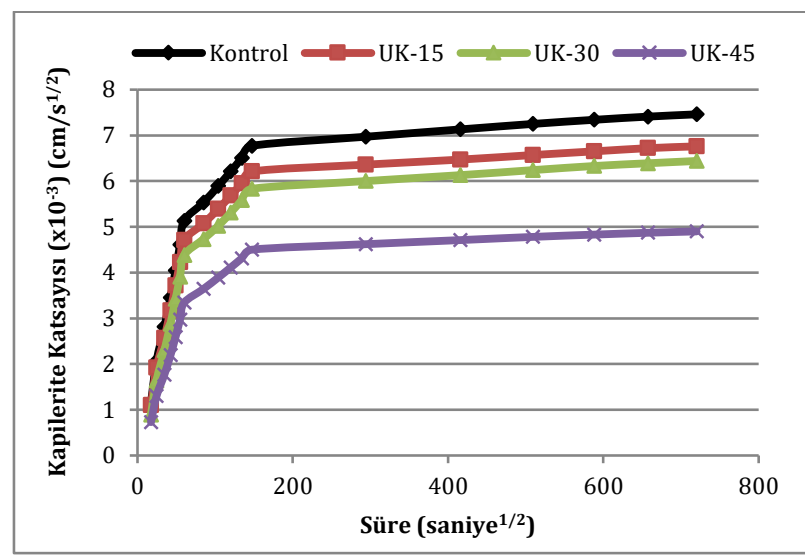

Şekil 8. Kontrol ve UK katkılı KYB karışımlarının kapiler yolla su emme deneyi sonuçları

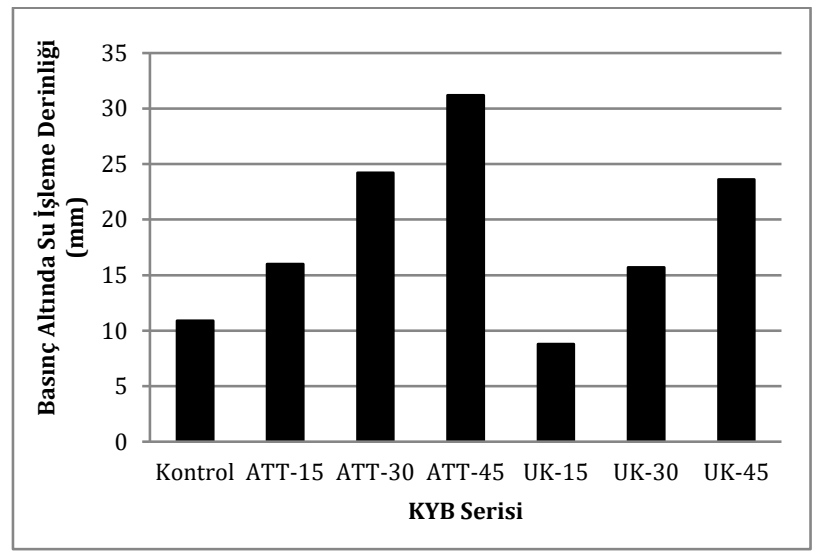

Şekil 9. KYB karışımlarının permeabilite deneyi sonuçları

KYB karışımlarının hızlı klor iyonu geçirimlilik deneyi sonuçları Şekil 10'da sunulmuştur. Betonda klor iyonu geçişi, betonun boşluk yapısı ve boşluk çözeltisinin kimyasal yapısı ile ilişkilendirilmektedir. Literatürde, farklı mineral katkıların klor iyonu geçiş özellikleri incelenmiş ve çoğu mineral katkının betonun klor iyonu geçişini azalttığı tespit edilmiştir [23]. Yapılan çalışmada da ATT ve UK kullanımının
KYB karışımlarının klor iyonu geçişlerini azalttığı belirlenmiştir. Kontrol karışımının klor iyon geçişi değeri 2181 Coulomb ölçülürken, \%15 ATT karışımında 1922 Coulomb, \%30 ATT karışımında 1427 Coulomb ve \%45 ATT karışımında ise 1211 Coulomb değeri ölçülerek, ATT oranı arttıkça KYB karışımlarında kademeli bir azalma meydana gelmiştir. UK katkılı karışımlarda ise klor iyon geçişi ATT katkılı karışımlardan daha düşük ölçülmüştür. $\% 15, \% 30$ ve $\% 45$ UK ikamesine sahip karıșımlarda klor iyon geçişi sırasıyla 1706 Coulomb, 1338 Coulomb ve 1088 Coulomb olarak belirlenmiştir.

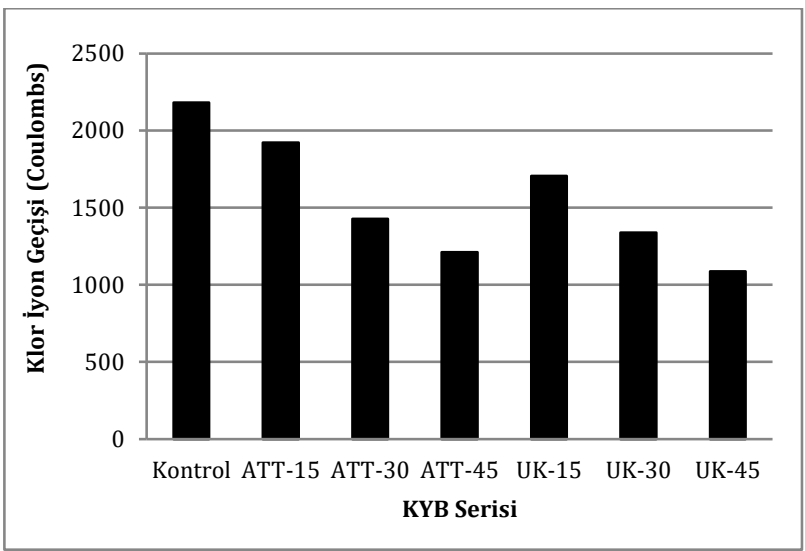

Şekil 10. KYB karışımlarının hızlı klorür iyonu geçirimlilik deneyi sonuçları

KYB karışımlarının donma-çözülme direnci deneyi sonuçları Şekil 11'de gösterilmiştir. Tüm karışımlarda donma-çözülme çevrim sayısı arttıkça betonlarda oluşan ağırlık kaybında artış gözlemlenmiştir. Hem ATT hem de UK katkılı KYB karışımlarının donmaçözülme etkisi sonucunda oluşan ağırlık kaybının kontrol karışımınkine göre daha az olduğu belirlenmiştir. ATT ve UK katkılı karışımlar karşılaştırıldığında ise, ATT katkılı karışımların ağırlık kaybının UK katkılı karışımlara göre daha az olduğu tespit edilmiştir. Deney sonuçlarına göre, 150 donma-çözülme çevrimi sonucunda kontrol karışımının ağırlık kaybı \%10.3 olarak ölçülürken, ATT'nin çimento yerine $\% 15, \% 30$ ve $\% 45$ ikame edilmesiyle elde edilen KYB karışımlarında ağırlık kaybı sırasıyla \%9.8, \%9.5 ve \%9.2 olarak belirlenmiştir. \%15, \%30 ve \%45 katkılı UK karışımlarının ağırlık kaybı ise sırasıyla \%10.1, \%9.7 ve \%9.5 olarak ölçülmüştür. Betonda donma-çözülme direncini etkileyen en önemli parametrelerden bir tanesi betonun boşluk yapısı olduğu bilinmektedir [18]. Bu çalışmada, KYB karışımlarının ultrases geçiş hızları belirlenmiş olup, tüm karışımlar arasında en düşük ultrases geçiş hızını ATT esaslı karışımlarda olduğu belirlenmiştir (Şekil 6). Böylece, ATT esaslı karışımların boşluk miktarının diğer karışımlara göre daha fazla olduğu söylenebilir. Bununla birlikte, KYB karışımlarının boşluk miktarı daha fazla olan ATT esaslı karışımların donma-çözülme direncinin daha fazla olduğu sonucuna varılabilir. 


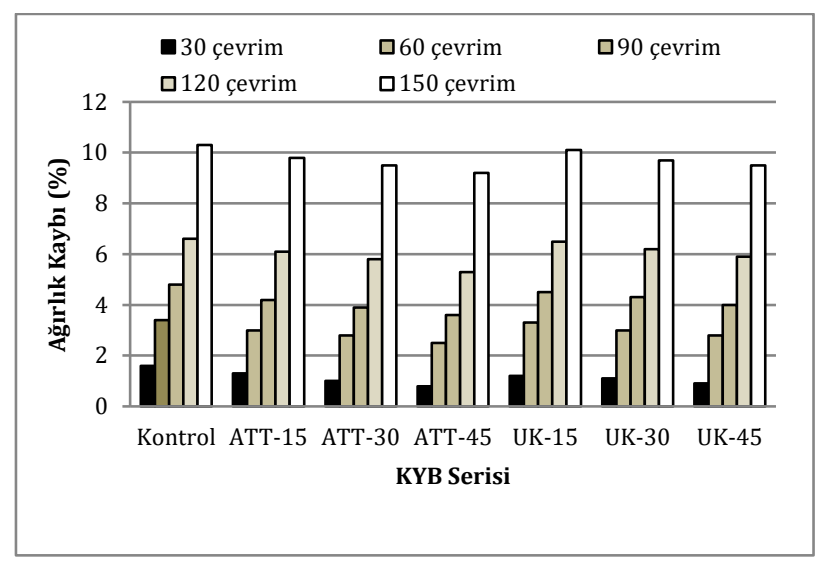

Şekil 11. KYB karışımlarının donma-çözülme direnci deneyi sonuçları

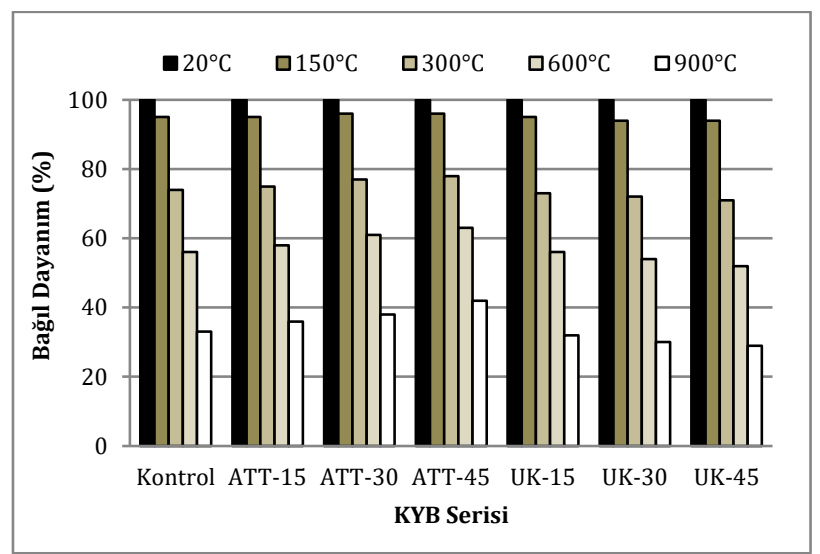

Şekil 12. KYB karıșımlarının yüksek sıcaklık direnci deneyi sonuçları

KYB karışımlarının yüksek sıcaklık direnci deneyi sonuçları Şekil 12'de verilmiştir. Tüm KYB karışımlarında sıcaklık arttıkça basınç dayanımlarında kademeli olarak bir azalma meydana gelmiștir. Kontrol karıșımında $150^{\circ} \mathrm{C}, 300^{\circ} \mathrm{C}, 600^{\circ} \mathrm{C}$ ve $900^{\circ} \mathrm{C}$ sıcaklıktaki dayanım kayıpları sırasıyla \%5, $\% 26, \% 44$ ve $\% 67$ mertebesinde gerçekleşmiştir. $\% 45$ ATT esaslı KYB karışımlarında $150^{\circ} \mathrm{C}, 300^{\circ} \mathrm{C}$, $600^{\circ} \mathrm{C}$ ve $900^{\circ} \mathrm{C}$ sicaklıktaki dayanım kayıpları sırasıyla $\% 4, \% 22, \% 37$ ve $\% 58$ olarak belirlenmiștir. ATT esaslı KYB karışımlarında ATT oranı arttıkça yüksek sıcaklık etkisinde dayanım kayıplarında bir azalma meydana geldiği tespit edilmiştir. ATT esaslı karışımlarında yüksek sıcaklık direncinin kontrol karıșımından daha yüksek olmasının iki nedeni olabileceği düşünülmektedir. Birincisi, yüksek sıcaklıklarda ATT'nin çimentoya göre daha kararlı bir yapıda olması [24], ikincisi ise ATT esaslı karışımların boşluk yapısının kontrol karışımından daha fazla olmasıdır. Daha fazla boşluk yapısına sahip karışımların yüksek sıcaklık dirençleri daha yüksek olmaktadır [22]. UK esash karışımlarda ise UK kullanım oranı arttıkça karışımların yüksek sıcaklık dirençlerinde bir azalma meydana geldiği gözlemlenmiștir. \%45 UK esaslı KYB karıșımlarında ise $150^{\circ} \mathrm{C}, 300^{\circ} \mathrm{C}, 600^{\circ} \mathrm{C}$ ve $900^{\circ} \mathrm{C}$ sicaklıktaki dayanım kayıpları sırasıyla $\% 6, \% 29, \% 48$ ve $\% 71$ olarak belirlenmiștir. Literatürde, UK'nın yüksek sıcaklıktaki termal kararlılığının ATT'den daha az olduğu belirlenmiştir [24]. Bunun sonucunda, UK katkılı KYB karışımlarının yüksek sıcaklık direncinin ATT katkılı KYB karışımlarına göre daha düşük çıktığı düşünülmektedir.

\section{Sonuçlar}

$\mathrm{Bu}$ çalışmanın amacı, atık tuğla tozunun mineral katkı olarak kullanılmasının kendiliğinden yerleşen betonun taze hal, mekanik ve durabilite özellikleri üzerine etkisinin araştırılmasıdır. Çalışmada kullanılan malzeme ve uygulanan deneylerden aşağıdaki sonuçlara varılmıştır.

- KYB karışımlarında sabit bir çökme yayılma değeri elde etmek amaciyla her KYB serisi için farklı miktarda süperakışkanlaştırıcı katkı maddesi kullanılmıştır. Atık tuğla tozu katkılı KYB karışımlarında süperakışkanlaştırıcı ihtiyacı kontrol karışımı ve uçucu kül katkılı karışımlara göre daha fazla olmuştur.

- V-hunisi ve L-kutusu deney sonuçlarına göre, atık tuğla tozu katkılı karışımlarda atık tuğla tozu kullanımı arttıkça KYB karışımlarının viskozitesi artmış ve geçiş özellikleri olumsuz etkilenmiştir. Atık tuğla tozu katkılı KYB karışımlarının taze hal özelliklerinin kontrol karışımı ve uçucu kül katkılı karışımlara göre daha zayıf olduğu sonucuna varılmıştır.

- Atık tuğla tozu esaslı karışımların 7 günlük basınç dayanımları kontrol karışımına göre atık tuğla tozu kullanım oranına bağlı olarak yaklaşık \%31'e kadar düşmüştür. 90 günlük ileri yaș basınç dayanımı sonuçlarında ise atık tuğla tozu kullanım oranına bağlı olarak dayanım kontrol karışımına göre yaklaşık \%14 daha düşük olmuştur.

- Çimento yerine atık tuğla tozunun \%15 ikamesi ile üretilen karışımın 90 günlük basınç dayanımı diğer atık tuğla tozu esaslı karışımlara göre kontrol karıșımının basınç dayanımına en yakın değeri almıştır.

- Atık tuğla tozu katkılı KYB karışımlarının basınç dayanımları uçucu kül katkılı KYB karışımlarının basınç dayanımlarına göre daha düşük değerler almıştır.

- Atık tuğla tozu içeren KYB karışımlarının eğilme dayanımı kontrol karışımından daha düşük çıkmıştır. Ancak, atık tuğla tozu esash karışımların eğilme/basınç dayanımı oranının kontrol ve uçucu kül katkılı karışımlardan bir miktar daha yüksek olduğu tespit edilmiștir.

- Ultrases geçiş̧ hızı deneyi sonuçlarına göre, atık tuğla tozu kullanımı KYB karışımlarının geçiş hızlarını azaltmıştır.

- Kılcallık ve basınç altında permeabilite deney sonuçları, atık tuğla tozu katkılı karışımların geçirimlilik özelliklerinin kontrol karışımı ve uçucu kül karışımlarına göre daha zayıf olduğunu göstermiştir. 
- Atık tuğla tozu katkılı KYB karışımlarının klorür iyonu geçirimliliğinin kontrol karışımından daha az olduğu tespit edilmiştir.

- Atık tuğla tozunun KYB karışımlarında mineral katkı olarak kullanım oranı arttıkça karışımların donma-çözülme direncinin arttığı belirlenmiştir.

- Atık tuğla tozu katkılı KYB karışımlarının yüksek sıcaklık direncinin kontrol ve uçucu kül katkılı KYB karışımlarına göre daha yüksek olduğu belirlenmiștir.

\section{Teşekkür}

Yazar, çalışmada kullanılan atık tuğlanın temininde katkı sağlayan Yüksel Toprak Sanayi ve Ticaret A.Ş.'ye teşekkür eder.

\section{Kaynakça}

[1] Okamura, H. 1997. Self-compacting highperformance concrete. Concrete International, 19(7), 50-54.

[2] Domone, P. L. J. 2007. A review of the hardened mechanical properties of self-compacting concrete. Cement and Concrete Composites, 29(1), 1-12.

[3] Şahmaran, M., Christianto, H. A., Yaman, İ. Ö. 2006. The effect of chemical admixtures and mineral additives on the properties of selfcompacting mortars. Cement and Concrete Composites, 28(5), 432- 440.

[4] Yamada, K., Takahashi, T., Hanehara, S., Matsuhisa, M. 2000. Effects of the chemical structure on the properties of polycarboxylatetype superplasticizer. Cement and Concrete Research, 30(2), 197-207.

[5] Domone, P. L. J. 2006. Self-compacting concrete: an analysis of 11 years of case studies. Cement and Concrete Composites, 28(2), 197-208.

[6] Uysal, M., Yılmaz, K. 2011. Effect of mineral admixtures on properties of self-compacting concrete. Cement and Concrete Composites, 33(7), 771-776.

[7] Le, T. H., Müller, M., Siewert, K., Ludwig, H. M. 2015. The mix design for self-compacting high performance concrete containing various mineral admixtures. Materials \& Design, 72, 5162.

[8] Rizwan, S. A., Bier, T.A. 2009. Self-compacting ortars using various secondary raw materials. ACI Materials Journal, 106, 1, 25-32.

[9] Wong, C.L., Mo, K.H., Yap, S.P., Alengaram, U.J., Ling, T.C., 2018. Potential use of brick waste as alternate concrete-making materials: A review. Journal of cleaner production, 195, 226-239.

[10] Heikal, M., Zohdy, K. M., Abdelkreem, M. 2013. Mechanical, microstructure and rheological characteristics of high performance self- compacting cement pastes and concrete containing ground clay bricks. Construction and Building Materials, 38, 101-109.

[11] European SCC Guidelines. 2005. Specifications and Guidelines for Self-Compacting Concrete. EFNARC, Association House, 99 West Street, Farnham, UK.

[12] TS EN 12390-3. 2010. Beton-Sertleşmiş beton deneyleri-Bölüm 3: Deney numunelerinin basınç dayanımının tayini, Türk Standartları Enstitüsü, Ankara.

[13] ASTM C597. 2016. Standard Test Method for Pulse Velocity Through Concrete. ASTM International, West Conshohocken, USA.

[14] ASTM C1585. 2013. Standard Test Method for Measurement of Rate of Absorption of Water by Hydraulic-Cement Concretes. ASTM International, West Conshohocken (USA).

[15] TS EN 12390-8. 2002. Beton - Sertleşmiş beton deneyleri - Bölüm 8: Basınç altında su işleme derinliğinin tayini, Türk Standartları Enstitüsü, Ankara.

[16] ASTM C1202. 2012. Standard test method for electrical indication of concrete's ability to resist chloride ion penetration. Annual Book of ASTM Standard, USA.

[17] ASTM C666. 1998. Standard test method for resistance of concrete to rapid freezing and thawing. Annual Book of ASTM Standard, USA.

[18] Bartos, P. J. M. 2005. Testing - SCC: Towards New European Standards For Fresh SCC. First International Symposium on Design, Performance and Use of Self Consolidating Concrete, Changsha, Hunan, China.

[19] Mehta, P. K., Monteiro, P. J. M. 2006. Concrete: Microstructure, Properties, and Materials. New York, U.S.A, The McGraw-Hill Companies.

[20] Naceri, A., Hamina, M.C., 2009. Use of waste brick as a partial replacement of cement in mortar. Waste management, 29(8), 2378-2384.

[21] Lin, K. L., Chiou, C. S., Chen, B. Y., Cheng, A. 2010. Waste brick's potential for use as a pozzolan in blended portland cement. Waste Management Research, 28(7), 647-652.

[22] Mindess, S., Young, J.F., Darwin, D. 2003. Concrete. Second Edition, Prentice Hall, 644p.

[23] Zhang, M.H., Bilodeau, A., Malhotra, V.M., Kim, K.S. and Kim, J.C., 1999. Concrete incorporating supplementary cementing materials: effect of curing on compressive strength and resistance to chloride-ion penetration. Materials Journal, 96(2), 181-189.

[24] Tuyan, M. 2017. Doğal ve atık malzemelerle geopolimer harç ve beton geliştirilmesi. Ege Üniversitesi, Fen Bilimleri Enstitüsü, Doktora Tezi, 291s, İzmir. 